\title{
Cognitive Functions, Self-Esteem and Self-Concept of Children with Attention Deficit and Hyperactivity Disorder
}

\author{
Funções Cognitivas, Autoestima e Autoconceito de Crianças \\ com Transtorno de Déficit de Atenção e Hiperatividade
}

\author{
Iuri Victor Capelatto*, Ricardo Franco de Lima, Sylvia Maria Ciasca \\ \& Cíntia Alves Salgado-Azoni \\ Universidade Estadual de Campinas, Campinas, São Paulo, Brasil
}

\begin{abstract}
The study aimed to compare the performance of children with ADHD and children without learning and/or attention difficulties in tasks of visual attention, executive functions, self-esteem and self-concept. Participants were34 children, 17 with ADHD and 17in the control group, with a mean age of 9.92 years. For the evaluation, the following tests were used: Cancellation Test, Trail Making Test, Stroop Color Word Test, Tower of London, Children's Depression Inventory, Self-Esteem Multidimensional Scale, and Children's Self-Concept Scale. The results indicated that children with ADHD showed worse out comes in attention and executive functions evaluations, in the belief of doing things the wrong way, in feelings of guilt and in low self-esteem, both in the general result as well as in self-perception.

Keywords: Attention deficit and hyperactivity disorder, cognition, self-esteem, self-concept, children.

Resumo

O estudo objetivou comparar o desempenho de crianças com TDAH e crianças sem queixas de aprendizagem e/ou atenção em tarefas de atenção visual, funções executivas, autoestima e autoconceito. Fizeram parte do estudo 34 crianças, sendo 17 com TDAH e 17 do grupo controle, com idade média de 9,92 anos. Para a avaliação, foram utilizados: Teste de Cancelamento; Trail Making Test; Stroop Color Word Test; Torre de Londres; Children's Depression Inventory; Escala Multidimensional de Auto-Estima, Escala de Autoconceito Infanto-Juvenil. Os resultados indicaram que crianças com TDAH apresentaram piores resultados nas avaliações atencionais, de funções executivas, na crença em fazer as coisas do jeito errado e sentimentos de culpa, e na autoestima, tanto no resultado geral como na Percepção de Si.

Palavras-chave: Transtorno da falta de atenção com hiperatividade, cognição, autoestima, autoconceito, crianças.
\end{abstract}

Attention Deficit and Hyperactivity Disorder (ADHD) is a neurobehavioral disorder of early onset, characterized by psychomotor restlessness, sustained attention difficulty and cognitive and social impulsivity. The main characteristics of ADHD are difficulties in maintaining attention on tasks that require concentration, completing tasks and remaining seated, low performance on assessments, disorganized material and work, constant speech, conversations and/or noises at inappropriate times, low performance in attentional and executive functions tasks (Barkley, 2008;

\footnotetext{
* Mailing Address: Departamento de Neurologia, Faculdade de Ciências Médicas, Universidade Estadual de Campinas, Rua Tessália Vieira de Camargo, 126, Caixa Postal 6111. Campinas, SP, Brasil 13083-970. E-mail: iuricapelatto@terra.com.br

Paper parcially presented on the XXI Nacional ABENEPI Congress - São Paulo/SP and on the 63rd Annual IDA Conference: Reading, Literacy and Learning International Congress de Baltimore, EUA
}

DuPaul \& Stoner, 2007; Eiraldi, Power, Karustis, \& Goldstein, 2000; Simão, Toledo, \& Ciasca, 2010).

ADHD has a pattern of inattention and/or hyperactivity/ impulsivity, which is more frequent and severe than in people at the same age development. In the last edition of the Diagnostic and Statistical Manual of Mental Disorders ([DSM-IV-TR], American Psychiatric Association, 2002), the disorder is divided into 3 subgroups: predominantly inattentive subtype, predominantly hyperactive/impulsive subtype and combined subtype. There is a problem of lack of self-control, with broad implications in the development, learning ability and social adaptation (Albert, López-Martín, Fernández-Jaén, \& Carretié, 2008; Cardo et al., 2010; López-Villalobos et al., 2007).

The manifestation of ADHD inattention component may be perceived as daydreaming, distractibility or focus difficulty on just one activity for a long period of time, lethargic behavior, lack of motivation, greater impairment 
in working memory, low performance in reading and understanding, internalizing symptoms (such as depression and anxiety), learning difficulties, perceptual-motor tasks, difficulties in focusing attention and cognitive disorder. Hyperactivity can be expressed by the child who is fidgeting all the time, excessive speech and activity, restlessness, difficulty on completing sequential tasks, higher reaction time, more school failure, motor and/or vocal agitation, controlling impulses and self-regulation difficulties and behavioral inhibition (Biederman et al., 1996; Simão et al., 2010). Children with ADHD often have low performance in attentional and executive functions tasks, as reported in studies concerning this disorder (Barkley, 2008; Ciasca, Rodrigues, \& Salgado, 2010).

ADHD is a common condition, multifactorial and complex etiology, with high prevalence rates when compared to other childhood disorders. It is believed that it affects approximately 3-5\% of children and adolescents population. It is a topic much studied in the literature regarding academic problems, behavioral, substance abuse and excessive absences at school (Barkley, 2008; Biederman, 2005; Biederman et al., 1996; Glass, Flory, Martin, \& Hankin, 2011; Mattos, Serra-Pinheiro, Rohde, $\&$ Pinto, 2006).

Regarding the models of which brain areas are involved in the disorder, first it was credited to the prefrontal-striatal areas as altered in ADHD subjects. Subsequently, it was discovered involvement of cerebellar areas. This occurred primarily because the prefrontal striatal circuits are responsible for the functioning of executive functions and the dysfunctions of these processes are correlated with ADHD (Castellanos \& Proal, 2012).

The network known as the executive control circuit, or fronto-parietal circuits, includes the lateral frontal lobe, the anterior cingulate cortex, dorsolateral and anterior prefrontal cortex, lateral cerebellum, anterior insula gyrus, caudate nucleus and inferior parietal lobe regions. This network involves functions such as mental flexibility (change responses in accordance with the change of context) and making decisions related to goals (Castellanos \& Proal, 2012), commonly altered in children with ADHD (Castellanos \& Proal, 2012; Ciasca et al., 2010).

The correct diagnosis of this disorder is crucial, since impairments may occur in quality of life of children and adolescents. Therefore, it should be done by an interdisciplinary team, which will evaluate all aspects related to the individual: neuropsychological, psychiatric, neurological, educational and speech. However, this takes time and is expensive (Ciasca et al., 2010).

\section{Depressive Symptoms, Self-Esteem and Self-Concept}

According to the definition of Coopersmith (Gobbita \& Guzzo, 2002), self-esteem is related to the assessment that the person does about him or herself, expressing approval or disapproval and indicates how capable he or she considers him or herself important and valuable. Thus, the concept is just a value judgment expressed by the attitudes that the individual cultivates for him or herself. However, the self-concept is defined as a multidimensional assumption resulting from the interaction of humans with the environments with which it interacts during the process of social construction, with self-assessment of their skills, accomplishments, experiences and representations (Sisto \& Martinelli, 2004).

The self-concept begins in childhood, is developed throughout life and is directly related to the impact of other's opinion. It is a construct broader than self-esteem because it includes cognitive (set of characteristics with what the person describes itself and that guides it way of being and guide itself), affective (also posted here as self-esteem, concerning the affection and emotions that come with the description of itself) and behavioral aspects (behavior influenced by the concept that a person has of him or herself), while the second component (self-esteem) is seen as more limited and evaluative of the first (Sisto \& Martinelli, 2004).

There are few data in the literature on self-esteem in children with ADHD, especially when considering the importance of this aspect in neuropsychological interventions. Studies on the functioning of the skills related to emotional competence in children with ADHD are scarce (Albert et al., 2008).

Gobitta and Guzzo (2002) claim that there are at least five reasons for the need to develop research focusing on self-esteem: it's a construct more complex than assumed; it is related to the psychological well-being and mental health; many negative mental elements, such as depression and suicide, are related to the absence or decline of self-esteem; it is relevant to the social sciences, and it is currently a concept with high social importance

It is common for people with ADHD have comorbid with other psychiatric disorders such as anxiety, mood changes (unipolar and bipolar depression or dysthymia) and school difficulties (Albert et al., 2008; Biederman, 2005; Biederman et al., 1996; Eiraldi et al., 2000; Krauel et al., 2009). Eiraldi et al. (2000) demonstrated in their study that $3.5 \%$ of children with ADHD showed depressive disorders.

Some studies with adolescents with ADHD symptoms and controls, showed that the former consider their psychosocial well-being worse, when referring to the life and their appearance satisfaction and to the condition of having close friends, which shows possible impact on their self-esteem (Taanila, Hurtig, Miettunen, Ebeling, \& Moilanen, 2009). However, research on the relationship of ADHD and the development of self-esteem are inconclusive, as some studies indicate that these individuals often have low self-esteem, and others report that children and adolescents with ADHD often overestimate their abilities, perceptions of self and self-concepts. Thus, as a protection mechanism, they enhance the appreciation of happiness that they feel with their lives (Glass et al., 2011; Miranda-Casas, Presentación-Herrero, Colomer-Diago, \& Roselló, 2011). 
Capelatto, I. V., Lima, R. F., Ciasca, S. M. \& Salgado-Azoni, C. A. (2014). Cognitive Functions, Self-Esteem and Self-Concept of Children with Attention Deficit and Hyperactivity Disorder.

Sisto and Martinelli (2004) describe that experience failure in performance on academic tasks can generate feelings of insecurity and lack of confidence in children, as studies are the main activity during childhood and adolescence. As it is characteristic of most children and adolescents with ADHD have an impact on school performance, it is likely to impact on the formation of school self-concept, which is related to the representations of one's accomplishments school abilities and assessments that the person does about them.

Children and adolescents with ADHD may have problems in skills that relate to emotional competence, such as recognition of facial expressions, emotional and affective prosody, regulation and expression of emotions. Studies show that these difficulties are related to the combined and hyperactive-impulsive subtypes, but there are no data regarding the inattentive subtype (Albert et al., 2008).

Krauel et al. (2009) found in their research that people with ADHD and comorbid oppositional defiant disorder or conduct disorder are often characterized by negative emotions and also seem to prefer to process negative information, particularly in social situations emotionally ambiguous.

These conditions lead to the importance of making a survey of self-esteem and self-concept of children with ADHD, related to possible changes in brain areas involved in attention and executive functions, influencing their social and educational development.

The aim of this study was to compare the performance of children with ADHD with children without learning and/or attention difficulties in tasks of visual attention, executive function, depressive symptoms, self-esteem and self-concept.

\section{Method}

\section{Participants}

This study enrolled 34 public school children, aged 8-13 years-old, (mean age: 9.92 years), attending middle school. Participants were divided into two groups: study group (SG), formed by 17 children with ADHD diagnosis; and control group (CG), formed by 17 children without attention and learning difficulties.

Children in SG were selected from referrals to the Laboratory of Learning Disabilities and Attention Disorder, State University of Campinas, Brazil. Initially, the children underwent diagnostic evaluation performed by an interdisciplinary team (child neurology, psychiatry, psychologist, speech therapist and pedagogue), according to the DSM-IV at time of evaluation, and were included in the study after confirming the diagnosis. The criteria for inclusion in these groups were as follows: consent form signed by the parents; ADHD diagnosis, presenting an intellectual level as expected, i.e., intelligence quotient (IQ) above 80; absence of sensory or motor deficits; not using psychotropic medication and having no other neurological symptoms. Initially, during the period of the study, 57 children with attention difficulties complaints were evaluated, and 40 were excluded for not confirming the diagnosis of ADHD or lack of continuity of the evaluation process or because the parents did not sign the consent form. Thus, the total study sample consisted of 17 children with interdisciplinary diagnostic of ADHD.

Children in CG, who were selected from the appointment of teachers at a school in the metropolitan region of Campinas/SP, should not have learning difficulties and poor academic performance. Children were selected accordingly, matched for age and sex with other groups and assessed in the school context. The criteria for inclusion in the group were as follows: a consent form signed by parents; no complaints about attention and learning difficulties and satisfactory academic performance; presenting an intellectual level as expected (i.e., intelligence quotient [IQ] above 80); no sensory or motor deficits, psychotropic medication and others neurological symptoms.

\section{Instruments}

Attention Evaluation. Cancellation Test (CT; Lima, Azoni, \& Ciasca, 2011; Lima, Travaini, \& Ciasca, 2009). A performance test that requires continuous rapid visual selectivity and repetitive motor response and aims to assess sustained visual-spatial attention. It was used two versions: (a) Geometric Figures (CT-GF): composed of a sheet with pseudo-random sequence, i.e., pseudo-random simple geometrical figures, in which the child had to mark all found circles (a total of 92) as fast as he could; (b) Letters in Row (CT-LR): composed of lyric sheets distributed at random, in which the child had to check all the letters "A" (a total of 60) as fast as he could. For both versions, there was no set time limit to perform the tasks. Scores were obtained: (a) Time: time in seconds that the child needs to perform the task; (b) Omission Errors: number of target stimuli that the child did not check; (c) Addition Errors: number of non-target stimuli the child checked.

Trail Making Test A (TMT-A; Lima et al., 2011; Lima et al., 2009; Spreen \& Strauss, 1998). Part A of TMT assesses visual sustained attention and is composed of a sheet with circles numbered 1 to 25 , and the child was randomly assigned to draw a line connecting the sequence of numbers as fast as he could. Scores were obtained: (a) Time: time in seconds to perform the task and (b) Number of Errors: number of links wrongly sequenced.

Executive Funtions Evaluation. Trail Making Test B (TMT-B; Lima et al., 2011; Lima et al., 2009; Spreen \& Strauss, 1998). Part B assesses mental flexibility and is composed of circles with numbers and letters. The child should draw a line alternately connecting the circles with numbers and letters, for example: 1-A-2-B-3-C, following the correct alphabetical and numerical order. Scores were obtained: (a) Time: time in seconds; (b) The number of sequencing errors: number of links with the wrong sequence of letters or numbers; and (c) Switching Errors: the number of times in which letters were alternated with numbers. Before collecting the data, it was verified whe- 
ther the children properly recognized numbers and letters randomly and sequentially.

Stroop Color Word Test - Victoria version (SCWT; Lima et al., 2011; Spreen \& Strauss, 1998). This test evaluates the ability of inhibitory control and selective visual attention. We used the four-color version (red, yellow, blue and green) and 24 stimuli in each of three parts: (a) "Color Card" (SCWT-C): with squares in four colors, using pseudorandom order; the child had to name the colors as quickly as possible; (b) "Words Card" (SCWT-W): with color names printed in colors corresponding to which the child had to name; (c) "Color-Word Card" (SCWT-CW): with names of colors, but printed in incongruent colors, for example, the word "green" printed in blue and the child had to say the name of the color and not read the word. Scores were obtained for time and errors for each of the cards, and additional scores were calculated: (a) Facilitation: the facilitation process obtained from the presentation of congruent stimuli. The score is obtained by subtracting time (facilitation-time) and error (facilitate-errors) scores: "color card" - "words card"; (b) Interference: which represents the "stroop effect" due to the incongruous situation of the test. The score is obtained by subtracting time (interference-time) and error (interference-errors) scores: "color-word card" - "color card".

Tower of London (ToL; Lima et al., 2011; Tunstall, 1999). The ToL assesses the mental ability to plan and consists of a wooden base with three vertical pins and three colored circles with a hole in the center to allow the groove on the pin. The goal is to rearrange the position of the circles from a fixed initial order to get different orders defined by the evaluator. Ten items showed increasing degree of difficulty depending on the number of moves needed to reach the final position. For each item, the examiner placed the circles in early position and then in final position; the child had to play using the fewest possible moves. The scores for each item could range from 1-3 points. The final score was expressed as the sum of scores for each item.

Depressive Symptomatology Evaluation. Children's Depression Inventory (CDI; Gouveia, Barbosa, Almeida, \& Gaião, 1995; Kovacs, 1992). Adapted for the Brazilian population, this inventory is widely used in epidemiological and clinical studies in Brazil and internationally. It is a self-assessment scale consisted of 20 items designed to identify depressive symptoms (affective, cognitive and behavioral) in children and adolescents of 7-17 years of age, using a cutoff of 17 for identifying significant symptoms. The subject must indicate one of three possible responses for each item, so that the score ranges from 0 (no symptoms) to 2 (severe symptoms). When applying with children, he/she is guided to select the item that best describes his/her feelings in the last two weeks and explanations are provided for any questions.

Self-Esteem and Self-Concept Evaluation. Multidimensional Scale of Self-Esteem (EMAE; Gobbita, 2003; Gobbita \& Guzzo, 2002). Translated from the instrument originally developed by Stanley Coopersmith in 1967 and 1989, this is a self-assessment inventory with 56 questions designed to identify the concept of self-esteem of children and adolescents aged 7-18 years. The individual must indicate for each question one of five alternatives, ranging from 0 to 5 points. The alternatives are related to each person's judgment as to that statement refers to his or her way of being, acting and/or thinking. The total maximum score for the overall scale is 280 points and the minimum of 56. The answers are divide into five dimensions, namely: Dimension 1 - Social acceptance, composed of 15 items that express judgments about characteristics of one's self on social relationships, such as social acceptance, socialization, social skills, extroversion, ability to influence the other, expression of own opinions, feelings expression, affections and moods, and others. Dimension 2 - Self Perception, with 15 items that express negative judgments about self's aspects, such as physical personal and social characteristics; Dimension 3 - Family, with 11 items that express judgments about characteristics of the relationships within the family, such as the acceptance or not, by parents, of his feelings and thoughts, and attention, care and affection perceived; Dimension 4-Performance, with 10 items that express judgments about the perceived characteristics of the personal performance, effectiveness and involvement in demands and expectations of the relational group, especially in the family and the school context; Dimension 5 - Self Acceptance, with 5 items that express judgments about self's characteristics, such as physical appearance and life satisfaction.

Self-Concept Scale for Children and Youth (EAC-IJ; Sisto \& Martinelli, 2004). This is a 20 questions self-assessment scale divided into 4 categories, which were personal self-concept, with 5 questions, social self-concept, with 5 questions, school self-concept, with 4 questions, family self-concept, with 6 questions. All questions must be answered with just one answer among three alternatives: always, sometimes, or never.

\section{Procedures}

First, the study was submitted to the Research Ethics Committee of the Faculty of Medical Sciences - University of Campinas (FCM-Unicamp) and accepted under opinion $\mathrm{n}^{\circ} 1016 / 2010$. The children were assessed individually by a single examiner in the rooms of the Outpatient Clinic of Neuro-Learning Difficulties or school, according to the group, and after parents signing the consent form. The tests were applied in the following sequence: cancellation test, stroop color word test, trail making test, the tower of London, CDI, EAC-IJ, EMAE. After the evaluations, the data were tabulated and went through descriptive (measures of central tendency and dispersion) and inferential statistics non parametric (Mann Whitney Test), using SPSS (Statistical Package for Social Sciences, version 20.0) and adopting a significance level of $5 \%$ (i.e., $p<.05$ ). 
Capelatto, I. V., Lima, R. F., Ciasca, S. M. \& Salgado-Azoni, C. A. (2014). Cognitive Functions, Self-Esteem and Self-Concept of Children with Attention Deficit and Hyperactivity Disorder.

\section{Results}

\section{Participants}

There was no statistically significant difference ( $p=$ .173) between the two groups of subjects regarding their ages, gender and grades (Table 1), but it's possible to observe that there were more boys than girls.

Attentional Evaluation

In attentional tests, it is worth mentioning that the longer and/or larger numbers of errors, the worse the test result. In Cancellation Test, the SG showed more difficulties in visual sustained attention, with more omission errors at Geometric Figures and at Letters in Row (i.e., some figures and letters were not crossed out), with a statistically significant difference in both parts of the test, as shown in Table 2.

Regarding the Trail Making Test (TMTA) - Part A, the SG showed worse performance than the CG with a higher number of errors, again demonstrating difficulty in visual sustained attention, which was statistically significant (Table 2).

Table 1

Sample Characterization

\begin{tabular}{|c|c|c|c|c|c|}
\hline \multirow{2}{*}{\multicolumn{2}{|c|}{ Variables }} & \multicolumn{2}{|c|}{ Groups } & \multirow{2}{*}{ Total } & \multirow[b]{2}{*}{$p$-value } \\
\hline & & SG & CG & & \\
\hline \multicolumn{6}{|l|}{ Gender } \\
\hline Male & $f(\%)$ & $15(88)$ & $10(59)$ & $25(74)$ & \multirow{2}{*}{$.118^{\mathrm{a}}$} \\
\hline Female & $f(\%)$ & $2(12)$ & $7(41)$ & $9(26)$ & \\
\hline \multicolumn{6}{|l|}{ Age } \\
\hline Mean age & $M(D P)$ & $10.42(1.83)$ & $9.43(1.05)$ & $9.92(1.55)$ & $.173^{\mathrm{b}}$ \\
\hline \multicolumn{6}{|l|}{ Grades } \\
\hline $2^{\text {th }}-4^{\text {th }}$ grades & & $8(47)$ & $8(47)$ & $16(47)$ & \multirow{2}{*}{$1.000^{\mathrm{a}}$} \\
\hline $5^{\text {th }}-7^{\text {th }}$ grades & & $9(53)$ & $9(53)$ & $18(53)$ & \\
\hline Total & & $17(50)$ & $17(50)$ & 34 (100) & \\
\hline
\end{tabular}

Note. Sig.: significance; $n$ : number of group subjects; SG: study group; CG: control group.

${ }^{\mathrm{a}}$ Fischer's Exact Test; ${ }^{\mathrm{b}}$ Mann-Whitney Test.

Table 2

Comparison of Average Attention Tests Scores among Groups

\begin{tabular}{|c|c|c|c|c|c|c|c|}
\hline \multirow{3}{*}{ Variable } & \multicolumn{6}{|c|}{ Group } & \multirow{3}{*}{$\begin{array}{c}\text { Sig. } \\
\text { ( } p \text {-value) }\end{array}$} \\
\hline & \multicolumn{2}{|c|}{ SG } & \multicolumn{2}{|c|}{ CG } & \multicolumn{2}{|c|}{ Total } & \\
\hline & Media & $S D$ & Media & $S D$ & Media & $S D$ & \\
\hline CT-GF Time & 94.59 & 31.00 & 83.71 & 11.98 & 89.15 & 23.80 & .228 \\
\hline CT-GF Omission Errors & 3.53 & 4.65 & .53 & 1.01 & 2.03 & 3.65 & $.008^{*}$ \\
\hline CT-GF Addition Errors & .12 & .49 & 7.71 & 31.52 & 3.91 & 22.28 & .552 \\
\hline CT-LR Time & 162.00 & 50.66 & 134.53 & 25.02 & 148.26 & 41.74 & .082 \\
\hline CT-LR Omission Errors & 8.71 & 5.83 & 2.76 & 4.15 & 5.74 & 5.82 & $.001 *$ \\
\hline CT-LR Addition Errors & .06 & .24 & .00 & .00 & .03 & .17 & .317 \\
\hline TMTA Time & 65.71 & 27.46 & 51.35 & 12.63 & 58.53 & 22.27 & .148 \\
\hline TMTA Errors & 1.41 & 1.94 & .06 & .24 & .74 & 1.52 & $<.001 *$ \\
\hline
\end{tabular}

Note. Mann-Whitney Test; Sig.: significance; CT-GF: Cancellation Test - Geometric Figures; CT-LR: Cancellation Test - Letters in Row; TMTA: Trail Making Test - Part A.

$* p<.01$. 


\section{Executive Functions Evaluation}

In mental flexibility and alternating attention evaluations, assessed by Trail Making Test (TMT)-Part B, the SG performance showed a statistically significant difference compared to the CG on all evaluated items, i.e., the group composed of subjects with ADHD required more time to perform the test, has committed more alternating and sequence errors, as shown in Table 3.

Table 3

Comparison of Average Executive Functions Tests Scores among Groups

\begin{tabular}{|c|c|c|c|c|c|c|c|}
\hline \multirow{3}{*}{ Variable } & \multicolumn{6}{|c|}{ Group } & \multirow{3}{*}{$\begin{array}{c}\text { Sig. } \\
\text { ( } p \text {-value) }\end{array}$} \\
\hline & \multicolumn{2}{|c|}{ SG } & \multicolumn{2}{|c|}{ CG } & \multicolumn{2}{|c|}{ Total } & \\
\hline & Media & $S D$ & Media & $S D$ & Media & $S D$ & \\
\hline TMTB Time & 256.76 & 102.06 & 143.65 & 49.89 & 200.21 & 97.74 & $.001^{* *}$ \\
\hline TMTB Switching erros & 3.12 & 3.35 & .18 & .53 & 1.65 & 2.80 & $<.001^{* *}$ \\
\hline TMTB Sequencing erros & 1.71 & 1.80 & .24 & .56 & .97 & 1.51 & $.003 * *$ \\
\hline SCWT-C Time & 27.24 & 15.47 & 17.24 & 4.02 & 22.24 & 12.23 & $.004^{* *}$ \\
\hline SCWT-C Errors & 1.41 & 1.77 & .18 & .39 & .79 & 1.41 & $.008 * *$ \\
\hline SCWT-W Time & 31.29 & 46.90 & 13.00 & 4.08 & 22.15 & 34.07 & $.001 * *$ \\
\hline SCWT-W Errors & .59 & 1.00 & .06 & .24 & .32 & .77 & $.016 *$ \\
\hline SCWT-CW Time & 55.47 & 30.70 & 35.53 & 9.38 & 45.50 & 24.54 & $.005^{* *}$ \\
\hline SCWT-CW Errors & 4.53 & 4.69 & 1.65 & 1.41 & 3.09 & 3.71 & $.021^{*}$ \\
\hline SCWT Interference Time & 28.24 & 20.66 & 18.29 & 6.70 & 23.26 & 15.94 & .068 \\
\hline SCWT Interference Errors & 3.12 & 4.47 & 1.47 & 1.28 & 2.29 & 3.34 & .248 \\
\hline SCWT Facilitation Time & -4.06 & 34.12 & 4.18 & 3.64 & .06 & 24.26 & .407 \\
\hline SCWT Facilitation Errors & .82 & 1.67 & .12 & .49 & .47 & 1.26 & .242 \\
\hline TOL & 16.47 & 3.74 & 21.76 & 2.54 & 19.12 & 4.14 & $<.001^{* *}$ \\
\hline
\end{tabular}

Note. Mann-Whitney Test; Sig.: significance, TMTB: Trail Making Test - Part B; SCWT-C: Stroop Color Word Test - Color Card; SCWT-W: Stroop Color Word Test - Words Card; SCWT-CW: Stroop Color Word Test - Color-Word Card; TOL: Tower of London. ${ }^{*} p<.05 ; * * p<.01$.

It is worth mentioning that, in the TMT - Part B, as well as attentional tests, the longer and/or higher number of errors, the worst result in the test.

In the Stroop, which evaluated the individual ability to select relevant stimuli and ignore irrelevant stimuli, the SG showed better performance difficulties regarding time and errors in the 3 cards. However, when comparing the interference and facilitation scores, there were no significant differences for these cases, as shown in Table 3. Again, it should be considered that the longer and/or higher number of errors, the worst result in the test.

This shows again that subjects with ADHD have more difficulties in visual sustained attention. However, when the impact of the incongruent stimulus was evaluated to verify the impact on visual selective attention, the level of interference was the same as the control group, with no statistically significant difference for visual selective attention on the Stroop effect.
In the evaluation of the mental ability to plan, the SG showed more difficulties in the Tower of London test, which was statistically significant (Table 3), noting that, in this test, the higher the result, the better the performance.

\section{Depressive Symptomatology Evaluation}

Depressive symptoms were assessed using the Children's Depression Inventory (CDI), in which the total result did not show statistically significant difference. However, the individually analysis of each question, there were statistically significant difference in 2 items of the CDI, which refer to CDI3 "subject's belief of doing things the wrong way" and CDI8: "feelings of guilt for bad things that happen”, cited in Table 4. In this test, the higher the score, the greater are the signs and the impact of depressive symptomatology. This shows that subjects with ADHD believe do more wrong things and feel more guilt for the bad things that happen. 
Capelatto, I. V., Lima, R. F., Ciasca, S. M. \& Salgado-Azoni, C. A. (2014). Cognitive Functions, Self-Esteem and Self-Concept of Children with Attention Deficit and Hyperactivity Disorder.

Table 4

Comparison of Average Depressive Symptoms CDI Scores among Groups

\begin{tabular}{|c|c|c|c|c|c|c|c|}
\hline \multirow{3}{*}{ Variable } & \multicolumn{6}{|c|}{ Group } & \multirow{3}{*}{$\begin{array}{c}\text { Sig. } \\
\text { (p-value) }\end{array}$} \\
\hline & \multicolumn{2}{|c|}{ SG } & \multicolumn{2}{|c|}{ CG } & \multicolumn{2}{|c|}{ Total } & \\
\hline & Media & $S D$ & Media & $S D$ & Media & $S D$ & \\
\hline CDI & 7.53 & 6.77 & 5.29 & 3.90 & 6.41 & 5.56 & .521 \\
\hline CDI 3 Wrong & .47 & .62 & .12 & .49 & .29 & .58 & $.025 *$ \\
\hline CDI 8 Guilt & .59 & .71 & .12 & .33 & .35 & .60 & $.022 *$ \\
\hline
\end{tabular}

Note. Mann-Whitney Test; Sig.: significance; CDI: Children‘s Depression Inventory.

${ }^{*} p<.05$.

Table 5

Comparison of Average EAC-IJ and EMAE Tests Scores among Groups

\begin{tabular}{|c|c|c|c|c|c|c|c|}
\hline \multirow{3}{*}{ Variable } & \multicolumn{6}{|c|}{ Group } & \multirow{3}{*}{$\begin{array}{c}\text { Sig. } \\
\text { ( } p \text {-value) }\end{array}$} \\
\hline & \multicolumn{2}{|c|}{ SG } & \multicolumn{2}{|c|}{ CG } & \multicolumn{2}{|c|}{ Total } & \\
\hline & Media & $S D$ & Media & $S D$ & Media & $S D$ & \\
\hline EACIJ Total & 23.76 & 5.29 & 26.24 & 4.15 & 25.00 & 4.84 & .162 \\
\hline EACIJ Personal Total & 4.71 & 1.61 & 5.53 & 1.59 & 5.12 & 1.63 & .163 \\
\hline EACIJ Scholar Total & 4.76 & 1.79 & 5.00 & 1.84 & 4.88 & 1.79 & .739 \\
\hline EACIJ Family Total & 5.24 & 1.48 & 5.18 & 1.78 & 5.21 & 1.61 & .792 \\
\hline EACIJ Social Total & 9.06 & 2.88 & 10.53 & 1.70 & 9.79 & 2.45 & .148 \\
\hline EMAE Total & 214.71 & 34.22 & 245.06 & 19.56 & 229.88 & 31.47 & $.006^{*}$ \\
\hline EMAE Media & 3.83 & .61 & 4.38 & .35 & 4.10 & .56 & $.006^{*}$ \\
\hline EMAE Dim 1 Total & 56.00 & 9.55 & 60.41 & 5.71 & 58.21 & 8.06 & .276 \\
\hline EMAE Dim 1 Media & 4.00 & .68 & 4.32 & .41 & 4.16 & .58 & .262 \\
\hline EMAE Dim 2 Total & 57.88 & 11.65 & 70.94 & 6.87 & 64.41 & 11.51 & $<.001^{*}$ \\
\hline EMAE Dim 2 Media & 3.54 & .78 & 4.43 & .43 & 3.99 & .77 & $<.001^{*}$ \\
\hline EMAE Dim 3 Total & 40.47 & 8.22 & 45.71 & 3.70 & 43.09 & 6.82 & .052 \\
\hline EMAE Dim 3 Media & 4.07 & .80 & 4.57 & .37 & 4.32 & .66 & .052 \\
\hline EMAE Dim 4 Total & 39.76 & 7.29 & 45.24 & 5.85 & 42.50 & 7.08 & .062 \\
\hline EMAE Dim 4 Media & 3.61 & .66 & 4.11 & .53 & 3.86 & .64 & .058 \\
\hline EMAE Dim 5 Total & 20.59 & 5.06 & 22.76 & 2.33 & 21.68 & 4.04 & .293 \\
\hline EMAE Dim 5 Media & 4.12 & 1.01 & 4.55 & .47 & 4.34 & .81 & .293 \\
\hline
\end{tabular}

Note. Mann-Whitney Test; Sig.: significance; EAC-IJ: Escala de Autoconceito Infanto-Juvenil; EMAE: Escala Multidimensional de Auto-Estima.

$* p<.01$. 


\section{Self-Esteem and Self-Concept Evaluation}

The self-concept evaluation occurred through EAC IJ, where the higher the score, the better the outcome. The total general and in each dimension results showed no statistically significant differences between groups. The same was true when comparing the results of the EAC- IJ quartile, in which there were no statistically significant differences in both the overall result as for all dimensions. In the assessment of self-esteem, there was a statistically significant difference in the overall total and average, and Dimension 2: Self Perception (items that express negative judgments about self's aspects, such as physical personal and social characteristics) in both the total result and the average (Table 5).

This demonstrates that, despite having ADHD, the SD had no significant impact on self-concept in relation to CG; however demonstrate impact on self-esteem of children with ADHD compared to the control group.

\section{Discussion}

This study found statistically non-significant differences by age, degree and gender, but it's possible to observe that there were an increased number of boys in the ADHD group. Several studies mention the difference between gender regarding diagnostic symptoms (Biederman et al., 2002; Dupuy, Barry, Clarke, McCarthy, \& Selikowitz, 2013). However, this study cannot claim such categorization by gender and subtype, since the sample of girls with the diagnosis is limited to the comparison. Based on the results, there were performance differences among ADHD children and the control group in different evaluations. Regarding sustained visual attention tests, the group of children with ADHD showed higher scores on omission errors on the Cancellation Test (geometric figures and letters in row), and errors on the Trail Making Test-A. It was not observed statistically significant difference on the commission errors among the groups, which is corroborated by the literature (Toledo, 2006).

These results suggest that children with ADHD have difficulties in tracking, requiring a greater solving time, which increases the number of errors. The results also corroborate the findings in the literature that indicate that children with ADHD show worse response pattern in visual-spatial attention tasks, in which cognitive resources are recruited for visual tracking, causing more errors (Toledo, 2006). Berwid et al. (2005) showed in a study of preschool children that the higher the omission errors, the greater the risk to have ADHD diagnosis, corroborating the finds cited above.

Regarding executive functions tests, children with ADHD showed worse results on all aspects on the TMT$-\mathrm{B}$, as required more time to solve the evaluation, as well as more alternation and sequence errors. Toledo (2006) also found difference between control group and ADHD children regarding the time and numbers of errors. She also highlights that TMT-B is more sensitive for cerebral dysfunction evaluation, and this difference on the time reflects the ADHD difficulties on tasks that demands inhibition and response planning, organization and alternating attention, which are difficulties associated to the frontal lobe. The learning difficulties of ADHD children may be revealed by neuropsychological evaluations, as well as slowness in alternating attention tasks. ADHD children have more errors and difficulties in planning and systematize their works.

These findings show that children with ADHD had more difficulties on mental flexibility. ADHD children had more difficulties on the TOL test compared to control group, indicating worse mental ability to plan, which are expected findings among children with this diagnosis (Barkley, 2008), since they have difficulties in working memory and executive inhibitory processes. It is necessary to have good planning abilities to perform well in TOL. These difficulties mentioned above disrupt this planning and anticipation, causing further errors and, consequently, reducing the total score in the test.

The SCWT test measures the ability to inhibit automatic responses, selecting relevant stimuli and ignore irrelevant stimuli (Lima et al., 2011; López-Villalobos et al., 2010). Regarding the selective attention (STROOP effect), children with ADHD showed higher scores on time and errors than control group, however the groups did not differ on the interference and facilitation factors, which suggests that the difficulty on the sustained attention leads to difficulties on the selective attention.

Toledo (2006) highlights that not all ADHD children show these difficulties in selective attention, what could explain why there was no difference when comparing to the control group on the interference factor. Chan et al. (2009) point that many studies have failed to show selective attention deficits compared to non-ADHD controls on SCWT test, except for studies with large samples, when group differences emerge, but they tend to be small effect sizes. They also discovered that children with ADHD displayed pronounced interference effects when the targets of the tests appeared on the right, and diminished interference effects when targets appeared on the left. On the other side, control group showed opposite results, with higher interference effects with targets on the left and less interference with targets on the right side.

Toledo (2006) also indicates that studies have shown the "participation of the parietal cortex in the information processing that demanded voluntary attention control, hypothesizing that the inferior parietal region is crucial for the onset of motor planning and plays a central role in the modulation of selective attention”. Other Brazilian study also showed results indicating latency changed on the selective attention, suggesting an attentional impairment over a cognitive problem (Simão, 2004).

These difficulties on the attention and executive functions tests are expected for children with ADHD 
Capelatto, I. V., Lima, R. F., Ciasca, S. M. \& Salgado-Azoni, C. A. (2014). Cognitive Functions, Self-Esteem and Self-Concept of Children with Attention Deficit and Hyperactivity Disorder.

(Barkley, 2008; Biederman, 2005; Ciasca et al., 2010; Simão, 2008; Toledo, 2006), and may be correlated with abnormal activation of frontostriatal circuits (Fernandez-Mayoralas, Fernandez-Jaen, Garcia-Segura, \& Quinones-Tapia, 2010).

Regarding assessments of depressive symptoms, self-concept and self-esteem, children with ADHD showed worse results only on items related to "subject's belief of doing things the wrong way" and "feelings of guilt for bad things that happen" (CDI); and EMAE: overall outcome and mean, and Dimension 2: Perception of Self (items that express negative judgments about yourself, such as physical, personal and social), both in total and on average result. The CDI and EAC-IJ total score did not show significant difference of the control group.

Some studies have showed that children with ADHD usually shows a positive illusory bias in their own personal perceptions regarding the operation in the academic, social and behavioral fields, and overvaluing the happiness they feel in their lives (Barkley, 2008; Miranda-Casas et al., 2011). These factors could explain why there were not differences on the self-concept and the CDI total scores.

Even so, it was possible to observe that children with ADHD feels more guilty, shows more belief in doing more wrong things and worse self-esteem. Once these children shows more difficulties on attention and executive functions, worse are the performance in schoolwork and everyday tasks, which can impact the development of self-esteem and causes more guilty feelings.

Further studies should consider increasing the sample groups, so that the level of interference on the emotional symptoms of cognitive functions can be checked.

\section{Conclusion}

This study was important to raise issues relating to performance evaluations of visual attention, executive function, depressive symptoms, self-esteem and self-concept in children with ADHD. Despite the limited number of children in groups, making it difficult to generalize the findings, this study suggests that children with ADHD may show difficulties in sustained visual attention tasks, especially regarding tracking, requiring a greater solving time, which increased the number of errors. They also showed difficulties in executive functions, especially on tasks that demands disinhibition and response planning, organization, alternating attention and mental flexibility, all functions related to frontal lobe. Regarding the depressive symptoms, self-esteem and self-concept evaluations, ADHD children showed more guilty, shows more belief in doing more wrong things and worse self-esteem, revealing the emotional impact that can cause ADHD in children if untreated. Further researches are needed to understand better the relationship between performance on attention and executive functions tasks and the development of self-esteem and self-concept of children with ADHD.

\section{Referências}

Albert, J., López-Martín, S., Fernández-Jaén, A., \& Carretié, L. (2008). Alteraciones emocionales en el trastorno por déficit de atención/hiperactividad: datos existentes y cuestiones abiertas. Revista de Neurología, 47, 39-45.

American Psychiatric Association. (2002). Diagnostic and statistical manual of mental disorders (DSM-IV-TR) $\left(4^{\text {th }} \mathrm{ed}\right.$.) Washington, DC: Author.

Barkley, R. A. (Ed.). (2008). Transtorno de déficit de atenção/ hiperatividade: Manual para diagnóstico e tratamento (3. ed.). Porto Alegre, RS: Artmed.

Berwid, O. G., Kera, E. A. C., Marks, D. J., Santra, A., Bender, H. A., \& Halperin, J. M. (2005). Sustained attention and response inhibitionin young children at risk for attention deficit/hyperactivity disorder. Journal of Child Psychology and Psychiatry, 46(11), 1219-1229

Biederman, J. (2005). Attention-deficit/hyperactivity disorder: A selective overview. Biological Psychiatry, 57, 1215-1220.

Biederman, J., Faraone, S. V., Milberger, S., Curtis, S., Chen, L., Marrs, A., ...Spencer, T. (1996). Predictors of persistence and remission of ADHD: Results from a four-year prospective follow-up study of ADHD children. Journal of American Academic Child Adolescent Psychiatry, 38, 966-975.

Biederman, J., Mick, E., Faraone, S. V., Braaten, E., Doyle, A., Spencer, T., ...Johnson, M. A. (2002). Influence of gender on attention deficit hyperactivity disorder in children referred to a psychiatric clinic. American Journal Psychiatry, 159, 36-42.

Cardo, E., Nevot, A., Redondo, M., Melero, A., Azua, B., Banda, G. G., \& Servera, M. (2010). Trastorno por déficit de atención/ hiperactividad: ?un patrón evolutivo? Revista de Neurología, 50(Supl. 3), S143-S147.

Castellanos, F. X., \& Proal, E. (2012). Large-scale brain systems in ADHD: Beyond the prefrontal-striatal model. Trends in Cognitive Sciences, 16(1), 17-26.

Chan, E., Mattingley, J. B., Huang-Pollock, C., English, T., Hester, R., Vance, A., \& Bellgrove, M. A. (2009). Abnormal spatial asymmetry of selective attention in ADHD. Journal of Child Psychology and Psychiatry, 50(9), 1064-1072.

Ciasca, S. M., Rodrigues, S. D., \& Salgado, C. A. (Eds.). (2010). TDAH: Transtorno do Déficit de Atenção e Hiperatividade (pp. 23-36). Rio de Janeiro, RJ: Revinter.

DuPaul, G. J., \& Stoner, G. (2007). TDAH nas escolas: Estratégias de avaliação e intervenção. São Paulo, SP: M. Books.

Dupuy, F. E., Barry, R. J., Clarke, A. R., McCarthy, R., \& Selikowitz, M. (2013). Sex differences between the combined and inattentive types of attention-deficit/hyperactivity disorder: An EEG perspective. International Journal of Psychophysiology, 89(3), 320-327.

Eiraldi, R., Power, T., Karustis, J., \& Goldstein, S. (2000, March). Assessing ADHD and comorbid disorders in children: The Child Behavior Checklist and the Devereux Scales of Mental Disorders. Journal of Clinical Child Psychology, 29(1), 3-16.

Fernandez-Mayoralas, D. M., Fernandez-Jaen, A., Garcia-Segura, J. M., \& Quinones-Tapia, D. (2010). Neuroimagen en el transtorno por deficit de atencion/hiperactividad. Revista de Neurología, 50(Supl. 3), S125-S133.

Glass, K., Flory, K., Martin, A., \& Hankin, B. (2011). ADHD and comorbid conduct problems among adolescents: Associations with self-esteem and substance use. Attention Deficit Hyperactivity Disorder, 3, 29-39. 
Gobbita, M. (2003). Escala multidimensional de auto-estima (EMAE): Construção e validação com crianças e adolescentes brasileiro (Tese de doutorado, Centro de Ciências da Vida, Pontifícia Universidade Católica de Campinas, Campinas, SP, Brasil).

Gobitta, M., \& Guzzo, R. S. L. (2002). Estudo inicial do Inventário de Auto-Estima (SEI) - Forma A. Psicologia: Reflexão e Crítica, 15(1), 143-150.

Gouveia, V. V., Barbosa, G. A., Almeida, H. J. F., \& Gaião, A. A. (1995). Inventário de Depressão Infantil - CDI: Estudo de adaptação com escolares de João Pessoa. Jornal Brasileiro de Psiquiatria, 44, 345-349.

Kovacs, M. (1992). Children Depression Inventory CDI: Manual. New York: Multi-Health Systems.

Krauel, K., Duzel, E., Hinrichs, H., Rellum, T., Santel, S., \& Baving, L. (2009). Emotional memory in ADHD patients with and without comorbid ADD/CD. Journal Neural Transmission, 116, 117-120.

Lima, R. F., Azoni, C. A. S., \& Ciasca, S. M. (2011). Attentional performance and executive functions in children with learning difficulties. Psicologia: Reflexão e Crítica, 24(4), 685-691.

Lima, R. F., Travaini, P. P., \& Ciasca, S. M. (2009). Amostra de desempenho de estudantes do ensino fundamental em testes de atenção e funções executivas. Psicopedagogia, 26(80), 188-199.

López-Villalobos, J. A., Serrano-Pintado, I., Andrés-De Llano, J. M., Delgado Sánchez-Mateos, J., Alberola-López, S., \& Sánchez-Azón, M. I. (2010). Utilidad del test de Stroop en el trastorno por déficit de atención/hiperactividad. Revista de Neurología, 50, 333-340.

López-Villalobos, J. A., Serrano-Pintado, I., Delgado Sánchez-Mateos, J., Ruiz Sanz, F., Sánchez-Azón, M. I., \& Sacristán Martín, M. A. (2007). Transtorno por déficit de atención/ hiperactividad: perfil intelectual y factor de independencia a la distracción. Revista de Neurología, 44(10), 589-595.

Mattos, P., Serra-Pinheiro, M. A., Rohde, L. A., \& Pinto, D. (2006). Apresentação de uma versão em português para uso no Brasil do instrumento MTA-SNAP-IV de avaliação de sintomas de transtorno do déficit de atenção/hiperatividade e sintomas de transtorno desafiador e de oposição. Revista de Psiquiatria, 28(3), 290-297.

Miranda-Casas, A., Presentación-Herrero, M. J., Colomer-Diago, C., \& Roselló, B. (2011). Satisfacción con la vida de niños con trastorno por déficit de atención/hiperactividad: estudio de posibles factores de riesgo y de protección. Revista de Neurología, 52(Supl. 1), S119-S126.

Simão, A. N. P. (2004). Avaliação neuropsicológica em crianças com transtorno e déficit de atenção e hiperatividade (Dissertação de mestrado, Faculdade de Ciências Médicas, Universidade Estadual de Campinas, Campinas, SP, Brasil).

Simão, A. N. P. (2008). Treino em solução de problemas com crianças que apresentam transtorno de déficit de atenção $e$ hiperatividade (Tese de doutorado, Faculdade de Ciências Médicas, Universidade Estadual de Campinas, Campinas, SP, Brasil).

Simão, A. N. P., Toledo, M. M., \& Ciasca, S. M. (2010). Transtornos de déficit de atenção e hiperatividade. In S. M. Ciasca, S. D. Rodrigues, \& C. A. Salgado (Eds.), TDAH: Transtorno do déficit de atenção e hiperatividade (pp. 23-36). Rio de Janeiro, RJ: Revinter.

Sisto, F. F., \& Martinelli, S. C. (2004). Escala de Autoconceito Infanto - Juvenil (EAC-IJ). São Paulo, SP: Vetor.
Spreen, O., \& Strauss, E. (1998). A compendium of neuropsychological tests- administration, norms and commentary. New York: Oxford University Press.

Taanila, A. M., Hurtig, T. M., Miettunen, J., Ebeling, H. E., \& Moilanen, I. K. (2009). Association between ADHD symptoms and adolescents' psychosocial well-being: A study of the northern Finland Birth cohort 1986. International Journal of Circumpolar Health, 68(2), 133-144.

Toledo, M. M. (2006). Comparação do diagnóstico e resposta a um treino de atenção em crianças com os subtipos de transtorno e déficit de atenção/hiperatividade (Tese de doutorado, Faculdade de Ciências Médicas, Universidade Estadual de Campinas, Campinas, SP, Brasil).

Tunstall, J. R. (1999). Improving the utility of Tower of London: A neuropsychological test of planning (Master's thesis of Philosophy, School of Applied Psychology, Faculty of Healthy Sciences, Griffith University, Queensland, Australia). 